\title{
СОВРЕМЕННЫЕ ТЕНДЕНЦИИ В СФЕРЕ ПРИВЛЕЧЕНИЯ ЧАСТНЫХ ВКЛАДОВ В КРЕДИТНЫЕ ОРГАНИЗАЦИИ РФ *
}

\author{
(C) 2019 Бабич Светлана Гаврииловна \\ кандидат экономических наук, доцент кафедры статистики \\ Российский экономический университет имени Г.В. Плеханова, Россия, Москва \\ E-mail: Babich.SG@rea.ru
}

В статье представлены результаты изучения динамики вкладов населения в кредитных организациях страны. Рассмотрена региональная структура депозитов физических лиц. Произведена группировка субъектов РФ по величине среднего размера одного вклада граждан. Выявлена зависимость среднего размера одного вклада в регионах страны от величины среднедушевых денежных доходов населения.

Ключевые слова: кредитные организации, вклады, физические лица, средний размер вклада, группировка, динамика, структура, зависимость.

В условиях сохранения антироссийских санкций со стороны отдельных государств, лишившись зарубежного фондирования, банки ведут все более активный поиск источников финансирования [4, с.174].

Вклады (депозиты) юридических и физических лиц играют значительную роль в формировании ресурсной базы кредитных организаций страны, денежные средства которых в условиях инновационного развития российской экономики будут способствовать технологическому преобразованию производства и повышению конкурентоспособности производимых товаров на международном рынке.

Важным источником поступления денежных средств в банковскую систему страны по-прежнему являются депозиты (вклады) населения, несмотря на снижение их удельного веса в течение 2018 г. с 49,1\% до 47,5\% в общем объеме средств клиентов, привлекаемых в кредитные организации РФ, а в общем объеме денежных доходов населения их доля возросла с $46,9 \%$ до $49,5 \%$ [7].

Личные накопления граждан становятся ресурсом не только для поддержания нормального функционирования ряда финансовых и нефинансовых организаций, осуществляющих посреднические функции в движении капитала, но и для дальнейшего развития российской экономики в целом [5, с. 27].

В течение 2018 г. объем вкладов населения в кредитных организациях страны возрос на 9,3\% и к началу 2019 г. составил по данным Банка Рос- сии 28518,14 млрд. руб. [7]. Позитивной тенденцией на рынке честных вкладов в 2018 г. является значительный рост (в два раза) депозитов сроком от 31 до 90 дней и от 181 дней до 1 года при сокращении в два раза объема вкладов сроком от 91 до 180 дней. В структуре вкладов физических лиц в стране по срочности по-прежнему пятую часть составляют вклады до востребования. Значительная часть депозитов - это средства, привлекаемые сроком от 1 года до 3 лет, несмотря на сокращение их удельного веса с $36,1 \%$ до 34,1\%. В течение 2018 г. существенно возросла доля частных вкладов сроком от 181 дня до 1 года с 20,3\% до 27,9\%, а удельный вес депозитов от 91 до 180 дней сократился с 16,3\% до 7,4\%. В то же время доля вкладов населения сроком свыше 3 лет не превышает 5,5\%, что явно недостаточно для формирования долгосрочных ресурсов банков (рисунок 1).

Наибольшее увеличение объема депозитов физических лиц отмечается в Дальневосточном федеральном округе (на 16,5\%), что обусловлено, по нашему мнению, вхождением в состав округа двух регионов страны, ранее находящихся в составе Сибирского федерального округа - Peспублики Бурятия и Забайкальского края. Несомненными лидерами по объему вкладов населения являются Центральный и Приволжский федеральные округа, в которых данный показатель возрос на $10,5 \%$ и 7,5\% соответственно. А наименьший объем частных вкладов зафиксирован в Северо-Кавказском федеральном округе (табл. 1).

BAK 08.00.05 


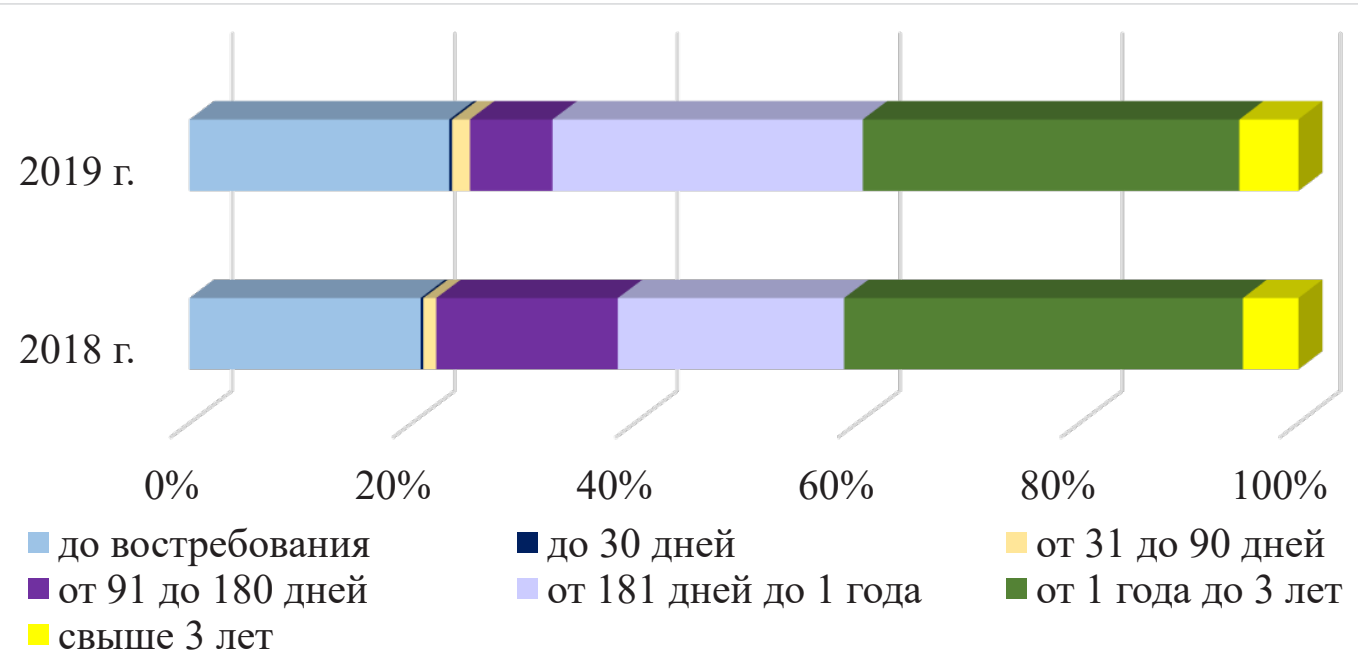

Puc. 1. Структура депозитов населения в кредитных организациях по срочности на начало года, в\% к итогу

Таблица 1. Динамика вкладов физических лиц в кредитных организациях РФ на начало года

\begin{tabular}{|l|c|c|c|}
\hline \multirow{2}{*}{ Федеральные округа } & Объем вкладов физических лиц, млрд. руб. & \multirow{2}{*}{ Темп прироста вкладов, \% } \\
\cline { 2 - 3 } & 2018 г. & 2019 г. & 10,2 \\
\hline Центральный & 12892,6 & 14209,9 & 10,0 \\
\hline Юеверо-Западный & 3042,5 & 3346,8 & 9,3 \\
\hline Южный & 1632,5 & 1784,7 & 8,1 \\
\hline Приволжский & 407,0 & 439,8 & 7,5 \\
\hline Уральский & 3363,4 & 3617,0 & 8,8 \\
\hline Сибирский & 1838,7 & 2000,8 & 2,3 \\
\hline Дальневосточный & 1949,6 & 1993,7 & 16,5 \\
\hline
\end{tabular}

Источник. Составлено и рассчитано по данным Банка России $[8,9]$.

Из регионов страны по темпу роста вкладов населения заметно выделяются Чукотский автономный округ, Республика Крым и Чеченской Республике, в которых объем депозитов в течение 2018 г. увеличился на 17,5, на 15,4\% и 14,5\%, а, например, в Карачаево-Черкесской Республике - только на $1,3 \%$.

Увеличение объема вкладов населения обусловлено, по нашему мнению, несколькими факторами. Во-первых, ростом денежных доходов населения, которые увеличились в течение 2018 г. в стране в целом на 7,2\%. Во-вторых, установлением суммы страхового возмещения в размере $100 \%$ от суммы вклада, но не более 1,4 млн. руб., в-третьих, сохранением доверия населения к банковской системе.

В общем объеме вкладов граждан преобладают депозиты в национальной валюте, удельный вес которых в течение 2018 г. сократился с $79,1 \%$ до $78,4 \%$, что обусловлено, по нашему мнению, опережающим темпом роста вкладов в иностранной валюте по сравнению с вкладами в рублях, т.к. депозиты населения в национальной валюте увеличились на $8,3 \%$, а в иностранной валюте - на 14,3\%. Наиболее существенный рост депозитов в рублях и иностранной валюте в относительном выражении отмечается в Дальневосточном федеральном округе - на $20,9 \%$ и 39,0\% соответственно (табл. 2).

Региональная структура депозитов физических лиц в кредитных организациях не претерпела существенных изменений. Несомненным лидером в данном сегменте является Центральный федеральный округ, удельный вес которого возрос с 49,4\% до 49,8\%, вторую позицию занимает Приволжский федеральный округ, доля которого сократилась с $12,9 \%$ до $12,7 \%$, а наименьший удельный вес вкладов отмечается в 
Таблица 2. Динамика вкладов физических лиц в федеральных округах РФ на начало года

\begin{tabular}{|c|c|c|c|c|c|c|}
\hline \multirow[t]{2}{*}{ Федеральные округа } & \multicolumn{2}{|c|}{$\begin{array}{c}\text { Объем вкладов в рублях, } \\
\text { млн. руб. }\end{array}$} & \multirow[t]{2}{*}{$\begin{array}{c}\text { Темп приро- } \\
\text { ста,\% }\end{array}$} & \multicolumn{2}{|c|}{$\begin{array}{c}\text { Объем вкладов в ино- } \\
\text { странной валюте, млн. } \\
\text { руб. }\end{array}$} & \multirow[t]{2}{*}{$\begin{array}{l}\text { Темп приро- } \\
\text { ста,\% }\end{array}$} \\
\hline & 2018 г. & 2019 г. & & 2018 г. & 2019 г. & \\
\hline Центральный & 9195396 & 10007304 & 8,8 & 3697230 & 4202578 & 13,7 \\
\hline Северо-Западный & 2435775 & 2655629 & 9,0 & 606693 & 691206 & 13,9 \\
\hline Южный & 1455262 & 1569417 & 7,8 & 177260 & 215293 & 21,5 \\
\hline Северо-Кавказский & 378082 & 408656 & 8,1 & 28885 & 31103 & 7,7 \\
\hline Приволжский & 2980295 & 3182003 & 6,8 & 383069 & 434954 & 13,5 \\
\hline Уральский & 1546373 & 1657536 & 7,2 & 292280 & 343215 & 17,4 \\
\hline Сибирский & 1775807 & 1811339 & 2,0 & 173760 & 182378 & 5,0 \\
\hline Дальневосточный & 873791 & 1056487 & 20,9 & 92611 & 128706 & 39,0 \\
\hline
\end{tabular}

Источник. Составлено и рассчитано по данным Банка России $[8,9]$.

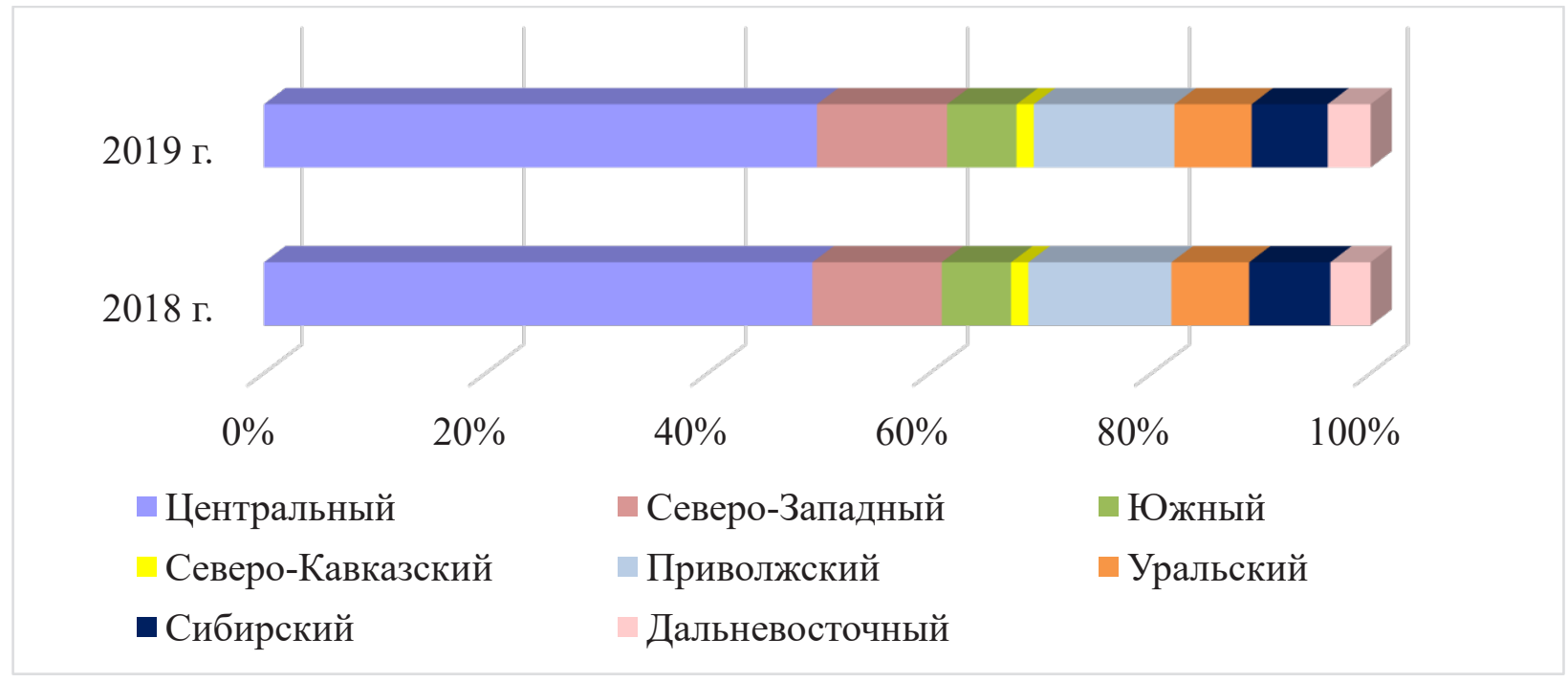

Puc. 2. Региональная структура вкладов физических лиц в кредитных организациях страны на начало года,\% к итогу

Северо-Кавказском федеральном округе - 1,6\% (рисунок 2).

В начале 2019 г. из субъектов РФ по удельному весу вкладов физических лиц в кредитных организациях страны лидирует г. Москва - 35,4\%, на втором месте - г. Санкт-Петербург (7,6\%), не третьем - Московская область (5,6\%).

Разнонаправленная динамика вкладов физических лиц в национальной и иностранной валюте обусловила незначительное сокращение удельного веса депозитов в рублях в общем объеме вкладов во всех федеральных округах страны, кроме Дальневосточного федерального округа, в котором данный показатель возрос на 3,4 п.п. (рисунок 3).

Для более объективного анализа уровня депонирования средств населения в кредитных организациях целесообразно, по нашему мне- нию, определить средний размер вкладов в расчете на душу населения.

Если в начале 2018 г. средний размер вклада граждан в РФ составлял 177,6 тыс. руб., то к январю 2019 г. возрос до 194,3 тыс. руб. (на 9,4\%).

В федеральных округах отмечается различная динамика среднего размера вклада в кредитных организациях страны. В Центральном федеральном округе средний размер вкладов в расчете на душу населения в 2018 г. увеличился на 10,0\%, составив 360,8 тыс. руб., а, например, в Северо-Кавказском федеральном округе - с 41,4 тыс. руб. до 44,6 тыс. руб., т.е. на 7,6\%. И только в Дальневосточном федеральном округе данный показатель сократился на 12,3\% до 137,4 тыс. руб., что, по нашему мнению, объясняется более низким объемом депозитов в расчете на душу населения в двух присоединенных субъек- 
Дальневосточный

Сибирский

Уральский

Приволжский

Северо-Кавказский

Южный

Северо-Западный

Центральный
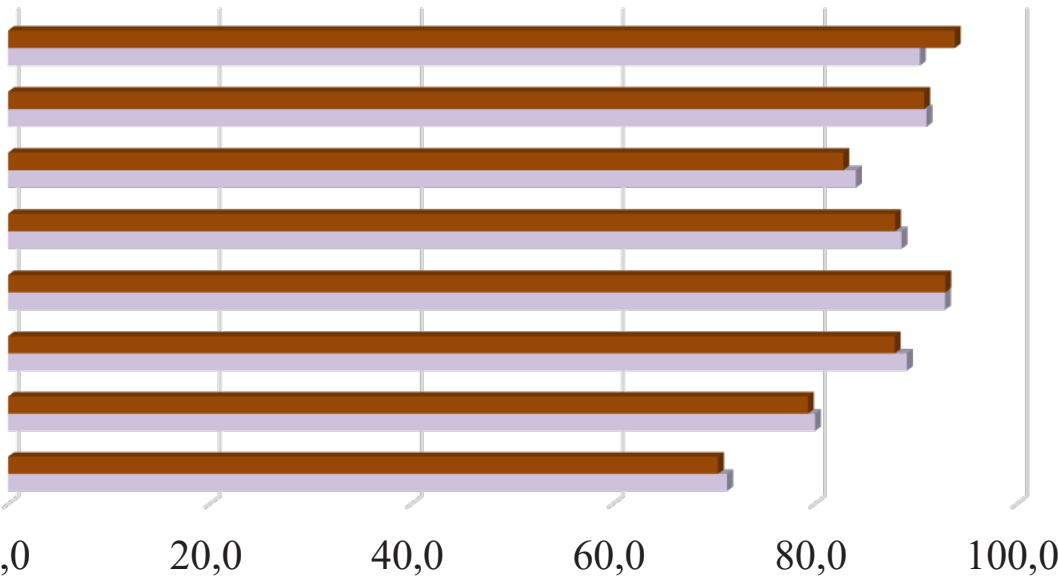

ロ 2019 г. $\square 2018$ г.

20,0

40,0

60,0

80,0

100,0

$\%$

Pис. 3. Динамика удельного веса вкладов в рублях в общем объеме депозитов населения в федеральных округах РФ на начало года,\%

\section{Дальневосточный \\ Сибирский \\ Уральский \\ Приволжский \\ Северо-Кавказский \\ Южный \\ Северо-Западный \\ Центральный}
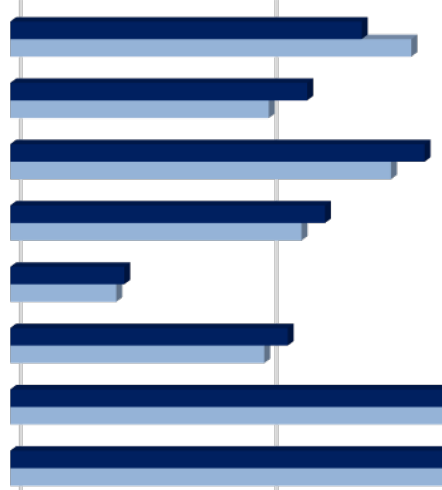

0,0

100,0

2019 г. $\quad 2018$ г

Puc. 4. Динамика среднего размера вклада в кредитных организациях федеральных округов РФ на начало года, тыс. руб.

тах - Республике Бурятия и Забайкальском крае (рисунок 4).

В стране наблюдается значительная региональная дифференциация по величине среднего размера вклада в кредитных организациях. По величине данного показателя 82 субъекты РФ разделены на 12 групп. В самую «слабую» первую группу вошел только один регион Северо-Кавказского федерального округа - Чеченская Республика, в которой средний размер вклада составил 9,16 тыс. руб. А максимальный средний размер одного вклада отмечается в двух городах федерального значения - г. Москва (799,99 тыс. руб.) и Санкт-Петербург (402,80 тыс. руб.). В 73 регионах страны средний размер вклада не превышает аналогичный показатель в целом по РФ (табл. 3).

Наиболее неблагоприятная ситуация в сфере привлечения вкладов населения наблюдается в Южном, Северо-Кавказском и Сибирском федеральных округах. Например, во всех регионах Северо-Кавказского федерального округа средний размер вклада физических лиц не превышает 100 тыс. руб. В Южном и Сибирском федеральных округах удельный вес регионов, в которых средний размер вклада менее 150 тыс. руб., со- 
Таблица 3. Группировка субъектов РФ по величине среднего размера вклада на начало 2019 г.

\begin{tabular}{|c|c|c|}
\hline $\begin{array}{c}\text { № } \\
\text { группы }\end{array}$ & $\begin{array}{l}\text { Средний размер } \\
\text { вклада, тыс. руб. }\end{array}$ & Субъекты РФ \\
\hline 1 & до 10 & Чеченская Респ. \\
\hline 2 & $10-30$ & Респ. Дагестан, Респ. Ингушетия, Респ. Тыва \\
\hline 3 & $30-50$ & $\begin{array}{l}\text { Респ. Калмыкия, Респ. Крым, Кабардино-Балкарская Респ., Карачаево-Чер- } \\
\text { кесская Респ., Респ. Алтай }\end{array}$ \\
\hline 4 & $50-75$ & $\begin{array}{l}\text { Респ. Адыгея, Респ. Северная Осетия-Алания, Респ. Бурятия, Забайкальский } \\
\text { кр., Курганская обл., г. Севастополь }\end{array}$ \\
\hline 5 & $75-100$ & $\begin{array}{l}\text { Респ. Башкортостан, Респ. Марий Эл, Респ. Мордовия, Респ. Хакасия, } \\
\text { Алтайский кр., Ставропольский кр., Астраханская обл., Брянская обл., } \\
\text { Ленинградская обл., Оренбургская обл., Псковская обл., Тамбовская обл.. } \\
\text { Еврейская авт. обл. }\end{array}$ \\
\hline 6 & $100-125$ & $\begin{array}{l}\text { Респ. Саха (Якутия), Удмуртская Респ., Чувашская Респ., Кировская обл., } \\
\text { Красноярский кр., Амурская обл., Волгоградская обл., Иркутская обл., Ке- } \\
\text { меровская обл., Костромская обл., Курская обл., Липецкая обл., Новгород- } \\
\text { ская обл., Омская обл., Орловская обл., Пензенская обл., Ростовская обл., } \\
\text { Саратовская обл., Смоленская обл., Тверская обл., Томская обл., Челябин- } \\
\text { ская обл., Ульяновская обл. }\end{array}$ \\
\hline 7 & $125-150$ & $\begin{array}{l}\text { Респ. Карелия. Респ. Татарстан, Краснодарский кр., Пермский кр., Бел- } \\
\text { городская обл., Владимирская обл., Вологодская обл., Воронежская обл., } \\
\text { Ивановская обл., Калужская обл., Рязанская обл., Тульская обл. }\end{array}$ \\
\hline 8 & $150-175$ & $\begin{array}{l}\text { Респ. Коми, Архангельская обл., Свердловская обл., Нижегородская обл., } \\
\text { Ярославская обл. }\end{array}$ \\
\hline 9 & $175-200$ & $\begin{array}{l}\text { Приморский кр.. Хабаровский кр., Калининградская обл., Новосибирская } \\
\text { обл., Самарская обл. }\end{array}$ \\
\hline 10 & $200-250$ & $\begin{array}{l}\text { Камчатский кр., Московская обл., Мурманская обл., Сахалинская обл., } \\
\text { Тюменская обл. }\end{array}$ \\
\hline 11 & $250-300$ & Чукотский авт. окр., Магаданская обл. \\
\hline 12 & более 300 & г. Москва, г. Санкт-Петербург \\
\hline
\end{tabular}

Источник. Рассчитано по данным Банка России и Росстата.

Таблица 4. Распределение регионов страны по величине среднего размера одного вклада физических лиц

\begin{tabular}{|c|c|c|c|c|c|c|c|c|c|}
\hline & 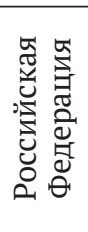 & 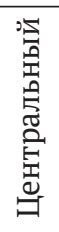 & 空 & 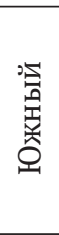 & 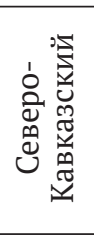 & 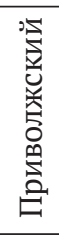 & 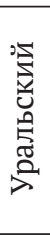 & 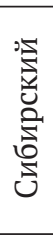 & 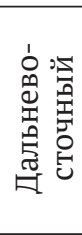 \\
\hline Число регионов - всего & 82 & 18 & 10 & 8 & 7 & 14 & 4 & 10 & 11 \\
\hline \multicolumn{10}{|c|}{ в том числе по среднему размеру вклада } \\
\hline до 10 & 1 & - & - & - & 1 & - & - & - & - \\
\hline $10-30$ & 3 & - & - & - & 2 & - & - & 1 & - \\
\hline $30-50$ & 5 & - & - & 2 & 2 & - & - & 1 & - \\
\hline $50-75$ & 6 & - & - & 2 & 1 & & 1 & - & 2 \\
\hline $75-100$ & 13 & 2 & 2 & 1 & 1 & 4 & - & 2 & 1 \\
\hline $100-125$ & 23 & 6 & 1 & 2 & - & 6 & 1 & 5 & 2 \\
\hline $125-150$ & 12 & 7 & 2 & 1 & - & 2 & - & - & - \\
\hline $150-175$ & 5 & 1 & 2 & - & - & 1 & 1 & - & - \\
\hline $175-200$ & 5 & - & 1 & - & - & 1 & - & 1 & 2 \\
\hline $200-250$ & 5 & 1 & 1 & - & - & - & 1 & - & 2 \\
\hline $250-300$ & 2 & - & - & - & - & - & - & - & 2 \\
\hline более 300 & 2 & 1 & 1 & - & - & - & - & - & - \\
\hline
\end{tabular}

Источник. Рассчитано автором. 
ставляет соответственно 100,0\% и 90,0\%. Население Дальневосточного федерального округа в большей степени депонирует значительные суммы имеющихся в распоряжении денежных средств, поскольку в четырех его субъектах средний размер вклада превышает аналогичный среднероссийский показатель (табл. 4).

Возможность размещения населением своих денежных средств во вклады и депозиты в кредитных организациях в значительной степени зависит от величины их денежных доходов. С помощью метода корреляционно-регрессионного анализа изучена зависимость среднего размера одного вклада физических лиц в регионах страны от величины среднедушевых денежных доходов населения. Полученные результаты свидетельствуют о наличии сильной прямой связи между рассматриваемыми показателями, т.к. по данным на начало 2019 г. линейный коэффициент корреляции $\left(r_{y x}\right)$ в целом по РФ составил 0,757 . Полученное значение коэффициента детерминации $\left(r_{y x}{ }^{2}\right)$, равное 0,573 , позволяет сделать вывод о том, что изменение объема среднего размера вклада физических лиц в кредитных организациях страны на $57,3 \%$ зависит от величины их денежных доходов, а на $42,7 \%$ от прочих факторов.

Необходимо отметить, что в большинстве федеральных округов страны отмечается сильная и очень сильная прямая зависимость между рассматриваемыми показателями. По данным на начало 2019 г. наиболее сильная прямая зависимость среднего размера вклада граждан от величины их денежных доходов отмечается в Центральном $\left(r_{y x}=0,920\right)$ и Уральском $\left(r_{y x}=\right.$ $0,969)$ федеральных округах, т.е. с ростом денеж- ных доходов граждан будут возрастать объем их депозитов в кредитных организациях региона. Если в Уральском федеральном округе изменение объема среднего размера вклада физических лиц в кредитных организациях региона на 93,9\% зависит от величины их денежных доходов, а на $6,1 \%$ - от прочих факторов, то для Приволжского федерального округа аналогичные показатели составляют 54,3\% и 45,7\% соответственно. И только в Северо-Кавказском федеральном округе денежные доходы граждан не оказывают влияние на объем депонируемых ими средств в кредитных организациях, что обусловлено, по нашему мнению, несколькими факторами: высоким уровнем безработицы, низким уровнем доходов населения и недостаточной институциональной обеспеченностью банковскими услугами в регионах округа (табл. 5).

Безусловно, объем денежных доходов населения оказывает существенное влияние на величину депозитов населения, но для увеличения объема привлекаемых средств граждан кредитные организации должны создавать более привлекательные условия для населения, например, увеличение процентных ставок по вкладам, расширение спектра предоставляемых банками услуг и повышение качества обслуживания клиентов. В настоящее время несмотря на низкую доходность по банковским вкладам по сравнению с уровнем инфляции, депозиты физических лиц для значительной части населения по-прежнему остается наиболее популярным видом финансовых вложений.

Процесс отзыва лицензий Банком России и сокращение банковских структур планомерно ведет к уменьшению неблагоприятных ситуа-

Таблица 5. Значения линейного коэффициента корреляции и детерминации, характеризующих зависимость среднего размера вклада физических лиц от величины среднедушевых денежных доходов населения в федеральных округах РФ на начало года

\begin{tabular}{|l|c|c|c|c|}
\hline \multirow{2}{*}{ Федеральные округа } & \multicolumn{2}{|c|}{$\begin{array}{c}\text { Значение линейного коэффициента } \\
\text { корреляции }\end{array}$} & \multicolumn{2}{c|}{$\begin{array}{c}\text { Значение коэффициента } \\
\text { детерминации }\end{array}$} \\
\cline { 2 - 5 } & 2018 г. & 2019 г. & 2018 г. & 2019 г. \\
\hline Центральный & 0,937 & 0,920 & 0,878 & 0,846 \\
\hline Северо-Западный & 0,860 & 0,874 & 0,740 & 0,764 \\
\hline Южный & 0,758 & 0,679 & 0,575 & 0,461 \\
\hline Северо-Кавказский & 0,157 & 0,242 & 0,025 & 0,059 \\
\hline Приволжский & 0,715 & 0,737 & 0,511 & 0,543 \\
\hline Уральский & 0,962 & 0,969 & 0,925 & 0,939 \\
\hline Сибирский & 0,667 & 0,775 & 0,445 & 0,601 \\
\hline Дальневосточный & 0,737 & 0,816 & 0,543 & 0,666 \\
\hline
\end{tabular}

Источник. Рассчитано по данным Банка России и Росстата. 
ций по потере накопленных средств населением, в связи с наличием и развитием системы страхования вкладов [6, с.127].

По прогнозам аналитиков Министерства экономического развития РФ, рост доходов населения повысит его сберегательные возможности. По отношению к ВВП доля рублевых депозитов населения повысится до 42-46\% к 2030 году. С учетом валютных депозитов совокупный объем депозитов населения составит 47-51\% ВВП [2]. По данным на начало 2019 г. данные показатели составляют 21,6\% и 27,5\% соответственно.

Как отмечалось в утвержденной Правительством РФ Стратегии развития финансового рынка Российской Федерации на период до 2020 года, сбережения граждан осуществляются пре- имущественно в виде вложений в иностранную валюту или на краткосрочные депозиты банков [1].

Неоднородность социально-экономического развития субъектов РФ обуславливает их существенную дифференциацию по основным рассматриваемым показателям на рынке привлекаемых кредитными организациями средств клиентов. Недостаточные объемы привлекаемых средств предприятий, организаций и населения во многих субъектах страны будут негативно влиять на процессы кредитования юридических и физических лиц, тормозить процессы инновационного развития экономики и модернизации промышленного производства [3, c. 85].

\section{Библиографический список}

1. Стратегия развития финансового рынка Российской Федерации на период до 2020 года. https://www.cbr.ru/ finmarkets/files/development/strategy_fm.pdf (дата обращения 1.03-12.03.2019).

2. Прогноз долгосрочного социально-экономического развития российской Федерации на период до 2030 года. http://static.government.ru/media/files/41d457592e04b76338b7.pdf (дата обращения 25.02-10.03.2019).

3. Бабич С.Г. Статистическое изучение основных источников привлечения средств клиентов в банковскую систему России // Вестник Российского университета дружбы народов. Серия: Экономика. 2013. № 2. С. $76-$ 86.

4. Актуальные направления развития банковского дела: монография/ Колл. авторов; под ред. Н.Э. Соколинской, И.Е. Шакер. Москва.2016.

5. Звонова Е.А. Банковские вклады как основной инструмент аккумуляции сбережений населения в современных условиях //Экономика. Налоги. Право. 2015. № 1. С. 27-36.

6. Никонец О.Е., Севрюкова С.В. Динамика институционального развития финансового рынка в системе трансформации инвестиционных и кредитных ресурсов // Вестник НГИЭИ. 2018. № 1 (80). С. $123-134$.

7. бзор банковского сектора Российской Федерации (Интернет-версия) № 196 февраль 2019 г. http://www. cbr.ru/Collection/Collection/File/14239/obs_196.pdf (дата обращения 25.02.2019-12.03.2019).

8. Статистический бюллетень Банка России № 1 (308) 2019. http://www.cbr.ru/Collection/Collection/File/14261/ Bbs1901r.pdf (дата обращения 25.02.2019-12.03.2019).

9. Статистический бюллетень Банка России № 1 (296) 2018. http://www.cbr.ru/Collection/Collection/File/7518/ Bbs1801r.pdf (дата обращения 25.02.2019-12.03.2019). 